\title{
Investigation of DMSD Trend in the ISS Water Processor Assembly
}

\author{
Layne Carter ${ }^{1}$ \\ NASA Marshall Space Flight Center, Huntsville, AL 35812 \\ Elizabeth Bowman ${ }^{2}$ \\ The Boeing Company, Huntsville, AL 35824 \\ Mark Wilson ${ }^{3}$ \\ The Boeing Company, Houston, TX 77058 \\ Greg Gentry ${ }^{4}$ \\ The Boeing Company, Houston, TX 77058 \\ Tony Rector ${ }^{5}$ \\ United Technologies Aerospace Systems, Windsor Locks, CT 06096
}

\begin{abstract}
The ISS Water Recovery System (WRS) is responsible for providing potable water to the crew, to the Oxygen Generation System (OGS) for oxygen production via electrolysis, to the Waste \& Hygiene Compartment (WHC) for flush water, and for experiments on ISS. The WRS includes the Water Processor Assembly (WPA) and the Urine Processor Assembly (UPA). The WPA processes condensate from the cabin air and distillate produced by the UPA. In 2010, an increasing trend in the Total Organic Carbon (TOC) in the potable water was ultimately identified as dimethylsilanediol (DMSD). The increasing trend was ultimately reversed after replacing the WPA's two multifiltration beds. However, the reason for the TOC trend and the subsequent recovery was not understood. A subsequent trend occurred in 2012. This paper summarizes the current understanding of the fate of DMSD in the WPA, how the increasing TOC trend occurred, and the plan for modifying the WPA to prevent recurrence.
\end{abstract}

\section{Introduction}

$\mathrm{T}$

he International Space Station (ISS) Water Recovery and Management (WRM) System insures availability of potable water for crew drinking and hygiene, oxygen generation, urinal flush water, and payloads as required. To support this function, waste water is collected in the form of crew urine, humidity condensate, and Sabatier product water, and subsequently processed by the Water Recovery System (WRS) to potable water. This product water is provided to the potable bus for the various users. The WRS is comprised of the Urine Processor Assembly (UPA) and Water Processor Assembly (WPA), which are located in two ISS Systems Payload Racks (ISPR), named

\footnotetext{
${ }^{1}$ Life Support Design Team Lead, NASA MSFC ES62.

2 . Lead Chemist \& Technical Lead Engineer, Boeing Huntsville Laboratories, Boeing Research \& Technology, JW56, Huntsville, AL 35824, Senior Member

${ }^{3}$ Associate Technical Fellow, Boeing Research \& Technology, 13100 Space Center Blvd., MC HB3-20, Houston, TX 77059, Senior Member.

${ }^{4}$ Engineering Lead, 13100 Space Center Blvd., MC HB3-20, Houston, TX 77059.

${ }^{5}$ Test Engineer, United Technologies Aerospace Systems, Windsor Locks, CT 06096.
} 
WRS\#1 and WRS\#2. A functional diagram of this system is provided in Figure 1. The WPA produces the potable water using a series of treatment processes as shown in Figure 2, primarily including Multifiltration (MF) Beds and a Catalytic Reactor. To insure the quality of the WPA product water, weekly samples are taken and subsequently analyzed for Total Organic Carbon (TOC) by the TOC Analyzer (TOCA). In May 2010, the TOCA data began an increasing trend that continued through October 2010, when the trend abruptly decreased as shown in Figure 3. Subsequent analysis of the potable water identified the source of the TOC increase as dimethylsilanediol (DMSD) ${ }^{1}$, an organosilicon compound that was not previously identified in the ISS condensate or UPA distillate. However, after detecting this compound in the product water, the Water And Food Analytical Laboratory (WAFAL) located at the Johnson Space Center analyzed current and archived samples of ISS condensate and determined that DMSD has been present since the WPA began operation on ISS in 2008. The source of DMSD is not obvious, and its fate in the WPA was unclear in 2010. The DMSD trend was repeated in 2012, providing correlating data to assist engineering and science personnel in identifying the root cause of this anomaly and developing a plan for modifying the WPA to remove it.

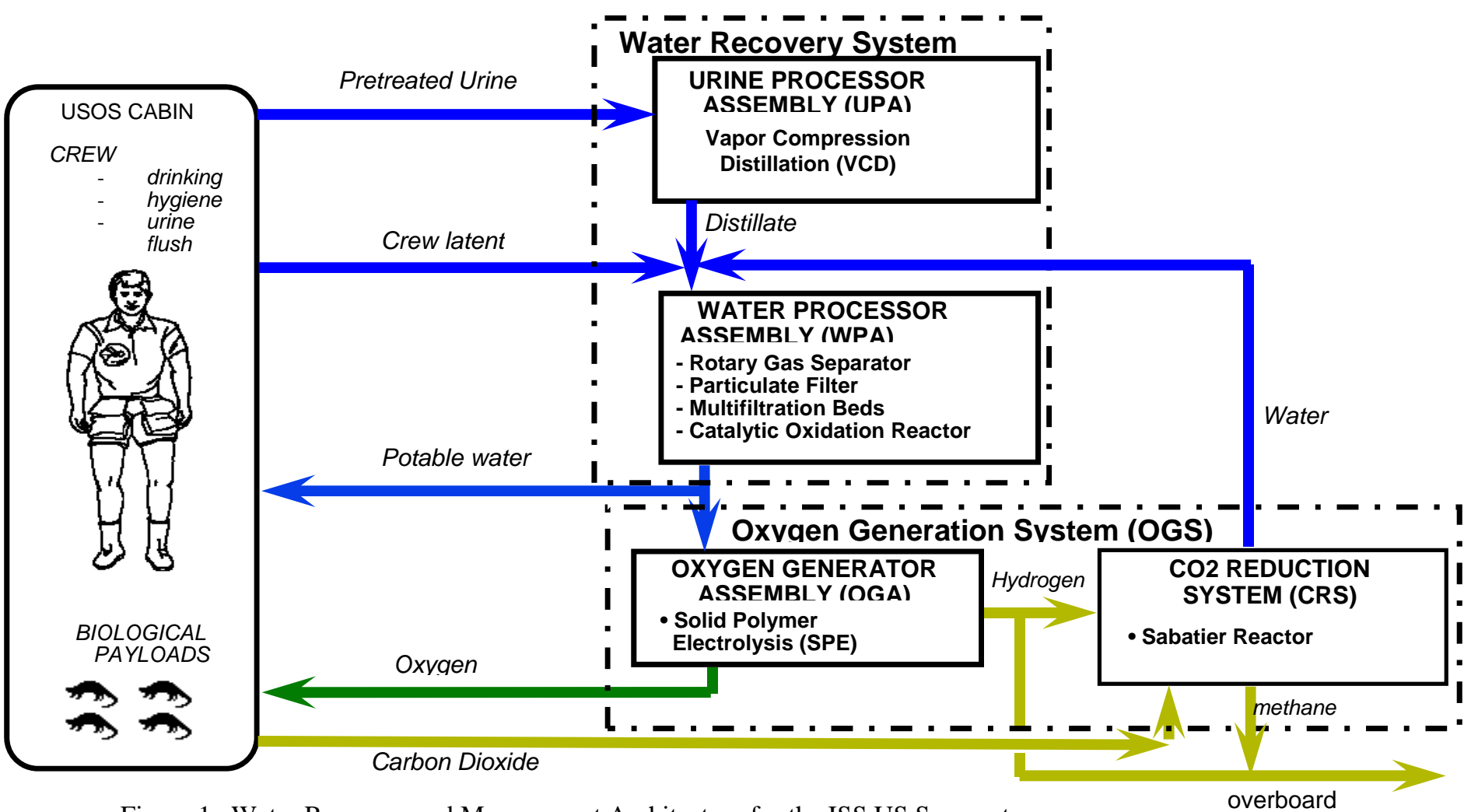

Figure 1. Water Recovery and Management Architecture for the ISS US Segment 


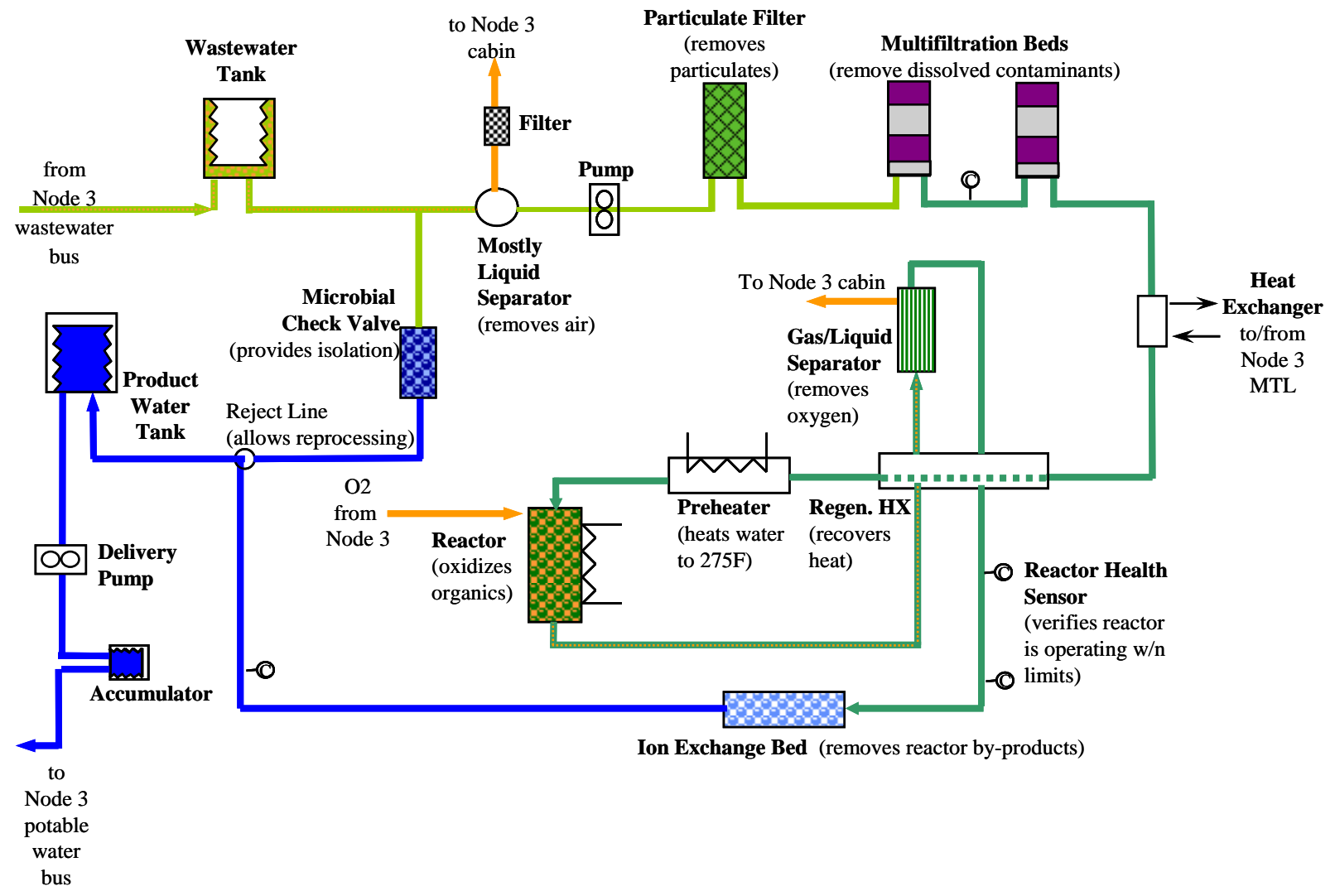

Figure 2. WPA Simplified Schematic

\section{Problem Description}

The primary questions related to DMSD include a) what is its source, b) how is it impacted by each treatment process in the WPA, and c) why does it exhibit the unique trend observed by the TOC Analyzer?

\section{A. DMSD Source}

Analyses of archive samples indicate DMSD has been prevalent in the ISS condensate and the WPA waste water for the life of the WPA (see Figure 4). Though DMSD is slightly volatile, analysis of atmospheric samples from the ISS cabin have not detected DMSD in the air. However, based on Henry's Law correlation, the concentration in the condensate would correlate to an atmospheric concentration of $<0.25 \mathrm{mg} / \mathrm{m}^{3}$, which is below the detection limit for the air monitors on ISS as well as on the ground ${ }^{2}$. Therefore it is possible that DMSD is volatilizing from a source (or sources) in the ISS cabin and condensing in the condensate. Another possibility is that DMSD is present in the atmosphere due to the degradation of polydimethylsiloxanes (PDMS) in the atmosphere. PDMSs are common compounds that offgas from various products present on ISS, including caulks, adhesives, lubricants, and hygiene products. Several PDMS compounds are routinely detected in the ISS atmosphere, including, hexamethylcyclotrisiloxane, octamethylcyclotetrasiloxane, and decamethylcyclepentasiloxane, and it is likely that other cyclic and linear siloxanes are also present in the atmosphere. Previous environmental studies have shown that decamethylcyclopentasiloxane will degrade in air to form $\mathrm{DMSD}^{3}$, indicating the possibility that DMSD is present in the atmosphere as a by-product of the degradation of one or more PDMSs in the air. Tbd, talk about the instability of DMSD in air ${ }^{4}$

Another possibility is that various PDMSs condense in the condensate and subsequently hydrolyze to DMSD. This reaction is expected to happen in the Condensing Heat Exchanger, as the PDMSs condense. This theory is based on the concentration of various PDMSs detected in the condensate, which is effectively at the solubility limit for these compounds. PDMSs have a relatively low solubility in water. For example, octamethylcyclotetrasiloxane, decamethylcyclopentasiloxane, and dodecamethylcyclohexasiloxane have a solubility of $0.056 \mathrm{mg} / \mathrm{L}, 0.017 \mathrm{mg} / \mathrm{L}$, 
and $0.005 \mathrm{mg} / \mathrm{L}$, respectively. Compared to the concentration of DMSD in condensate (typically 20 to $60 \mathrm{mg} / \mathrm{L}$ ), it is obvious that the reaction to form DMSD must occur in the Condensing Heat Exchanger, where there is an ample supply of PDMS in the air to continually produce DMSD in the condensate. In summary, it is expected that some quantity of PDMSs are hydrolyzing as they are condensed to form DMSD.

The unresolved issues with this theory include which specific PDMSs are hydrolyzing to form DMSD and the potential role of the Condensing Heat Exchanger coating in the reaction. The reaction to form DMSD may be a simple hydrolysis reaction in the condensate, though personnel at JSC have been unable to reproduce this reaction with any of the cyclic siloxanes commercially available. DMSD has been produced in the laboratory by hydrolysis with dimethoxydimethylsilane $\left(\mathrm{C}_{4} \mathrm{H}_{12} \mathrm{O}_{2} \mathrm{Si}\right)$, which readily replaces the methoxy groups in water with a hydroxyl group to form DMSD. However, the concentration of dimethoxydimethylsilane in the air $\left(\sim 300 \mathrm{mg} / \mathrm{m}^{3,2}\right)$ required to produce the levels of DMSD observed in the condensate appear to unrealistic. A more credible explanation is that the hydrolysis reaction is catalyzed by the coating on the Condensing Heat Exchanger. This reaction is more consistent with the fate of PDMS in the environment, in which PDMSs degrade to form DMSD in the soil ${ }^{5,6}$. The heat exchanger coating contains metal silicates that have been shown to catalyze the hydrolysis reaction of PDMS to DMSD in soils ${ }^{7,8}$. This research also identified an increase in PDMS degradation related to dry cycles in the soil due to drought conditions. Since the Condensing Heat Exchanger is dried monthly on ISS for microbial control, it is possible this activity may also be contributing to the production of DMSD in the condensate. This research provides rationale for suspecting that a similar reaction may occur as the PDMS condense on the coating. To evaluate this theory, ground tests will be performed on the coating from the Condensing Heat Exchanger in various environments to characterize its contribution to the hydrolysis reaction. If these tests can provide further information on the specific path by which DMSD is produced, engineering personnel may be able to resolve this problem by developing a treatment process that will eliminate or significantly reduce DMSD in the ISS condensate.

The possibility that the heat exchanger coating is contributing to the formation of DMSD is interesting given previous investigations into the effect of PDMS on the coating. The coating is hydrophilic, which is essential for the collection and transport of condensate in microgravity. Over time, the Condensing Heat Exchangers on ISS have degraded as the coating becomes less hydrophilic, resulting in condensate sloughing off the coating and into the air duct. An evaluation of a failed heat exchanger from ISS identified various contaminants adsorbed into the coating, including various PDMS $^{9}$. This is not unexpected, as the coating itself includes a wetting agent that is known to capture organosilicon compounds. It is conjectured that PDMS is contributing to the heat exchanger failure by impacting the hydrophilicity of the coating. This data further supports the premise that the heat exchanger may be a critical link in the degradation of PDMS to DMSD. Furthermore, this connection with the performance of the Condensing Heat Exchanger provides impetus to remove PDMS in the air, and thereby address the potential degradation of the coating while also preventing DMSD from entering the condensate. 


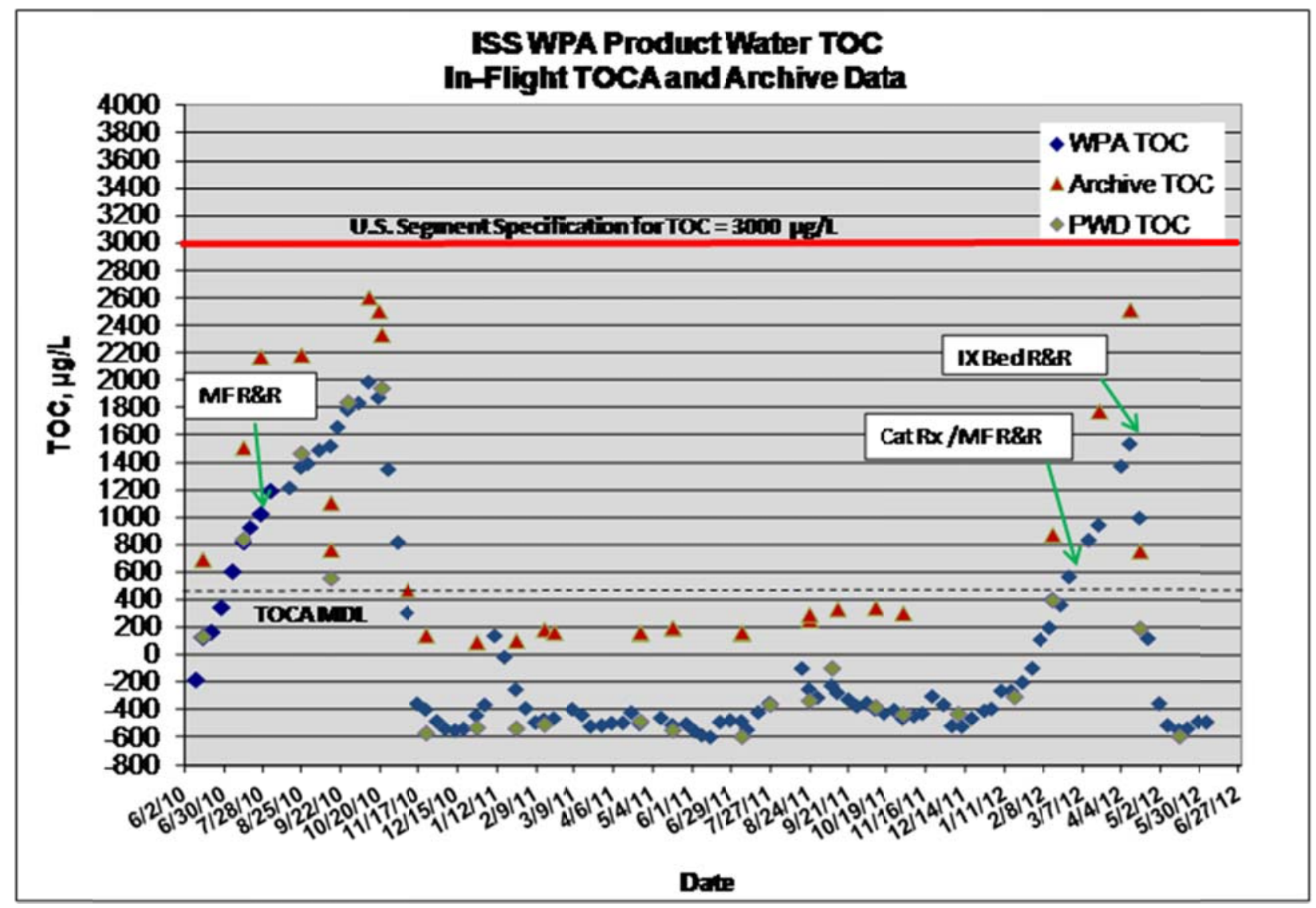

Figure 3. TOC Trend in WPA Product Water

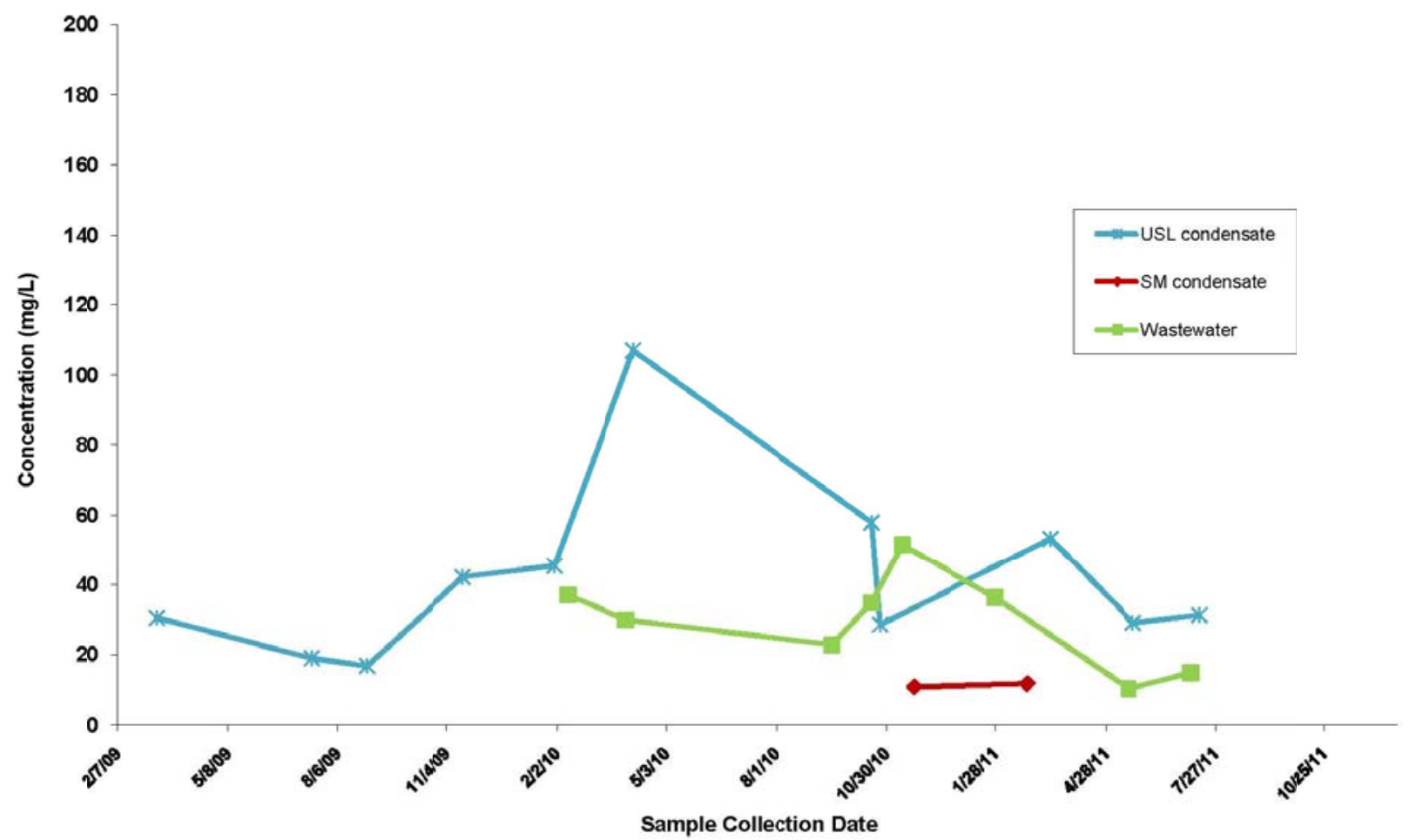

Figure 4. DMSD in ISS Condensate and WPA Waste Water 


\section{B. Treatment of DMSD in the WPA}

There are several treatment processes in the WPA that affect DMSD, including the Multifiltration Beds, the Catalytic Reactor, and the Ion Exchange Bed. Limited data is available for quantifying the capacity of the MF Beds for DMSD. As a polar, low molecular organic, DMSD is not expected to be well removed by adsorption or ion exchange, a statement that is corroborated by the fact that the contaminant also quickly passed through another cartridge containing ion exchange resin and adsorbent media. This hardware (identified as the ACTEX cartridge) is located upstream of the ISS Potable Water Dispenser for removing iodine from the WPA product water before crew consumption, and was replaced during the TOC trend as part of routine maintenance. The results in Figure 2 show a momentary decrease in DMSD followed by a return to the same trend, thus displaying the fact that DMSD is not effectively removed by adsorbent or ion exchange media.

Analysis of waste water samples show the average concentration of DMSD in the waste water is approximately $20 \mathrm{mg} / \mathrm{L}$. Samples of the MF Bed effluent have been taken immediately prior to removal of the MF Beds in 2010 and 2012, and again shortly after the new MF Beds were installed. This data is summarized in Table1, and indicates the DMSD concentration in the MF Bed effluent is approximately $40 \mathrm{mg} / \mathrm{L}$ when the beds are saturated with DMSD. Analysis of MF Bed effluent samples taken after the new MF Beds were installed showed the MF Beds were still effectively removing DMSD after $760 \mathrm{~L}$ of throughput. This result indicates the MF Beds do have some limited capacity for DMSD. However, analysis of the Ion Exchange Bed performance indicates DMSD is being preferentially removed by bicarbonate in the ion exchange resin. If this is the case, then it appears the passage of bicarbonate through the MF Bed is resulting in DMSD being pushed off the ion exchange media and into the reactor. This theory is corroborated by the fact that the concentration in the MF Bed effluent samples is statistically greater than the concentration in the waste water sample, since the concentration of DMSD in the MF Bed effluent would include both the DMSD in the waste water as well as the DMSD preferentially removed by bicarbonate in the MF Beds.

Chemical analysis of MF Beds S/N 0003 and 0004, which were the first two MF Beds installed in the WPA, elucidated the extent to which breakthrough occurred for several chemical species, including silicon containing organic compounds like siloxanes, silanes, and DMSD. These analyses are detailed elsewhere (refer to $42^{\text {nd }}$ and $43^{\text {rd }}$ ICES papers). In summary, DMSD is only weakly retained by the MF Bed adsorbent and ion exchange resins. Its small size, high water solubility, and primarily neutral character allow DMSD to be easily displaced by species that are more strongly adsorbed. The small capacity of the MF Beds for DMSD was exceeded, and this compound is present throughout both beds and the components downstream of them. This indicates a need for modifications to either the MF Bed or some other component of the WPA to better remove DMSD so that the MF Beds can be utilized to their full capacity as originally designed. Polysiloxanes appear to be better retained than DMSD, and they are best retained on the adsorbent in tubes 1 through 3 when there is little competition from other compounds, i.e. they are retained in tubes 2 and 3 after many of the other organic compounds have been removed in tube 1 . In both MF Beds S/N 0003 and S/N 0004, there is a peak in siloxane compounds mid-bed. This is likely caused by competition for ion exchange sorption sites that causes the silanes and siloxanes to move further through the bed. This also indicates that even though the adsorbent in tubes 1 through 3 is not saturated with respect to organics in general, it does appear to be saturated with respect to siloxanes. Otherwise, siloxanes would not have been observed further downstream in the middle of MF Bed S/N 0003. Large siloxanes (including hexamethylcyclotrisiloxane, octamethylcyclotatrasiloxane, decamethylcyclopentasiloxane, and other unidentified siloxanes) were also found in the first three tubes of the second bed, indicating that siloxanes did break through or saturate the first bed. The data also show that it is unlikely that large silane / siloxane compounds are passing through the second bed to reach the catalytic reactor. If the MF Beds were used to their full capacity to remove ionic and organic compounds (other than siloxanes) without modification, it is likely that the siloxanes would be pushed downstream through the bed, eventually appearing in the MF Bed effluent.

Table 1. Summary of ISS MF Bed Effluent Analyses

\begin{tabular}{|l|l|l|l|l|}
\hline Sample Date & $\mathbf{0 7 / 2 9 / 2 0 1 0}$ & $\mathbf{1 0 / 2 8 / 2 0 1 0}$ & $\mathbf{0 3 / 0 7 / 2 0 1 2}$ & $\mathbf{0 3 / 2 0 / 2 0 1 2}$ \\
\hline Contaminant & Pre R\&R* & Post R\&R & Pre R\&R & Post R\&R \\
\hline MF Bed Throughput & $4630 \mathrm{~L}$ & $760 \mathrm{~L}$ & $4840 \mathrm{~L}$ & $170 \mathrm{~L}$ \\
\hline Acetone & 4690 & $<2$ & 3440 & $<20$ \\
\hline
\end{tabular}




\begin{tabular}{|l|l|l|l|l|}
\hline Ethanol & 13600 & 15300 & 30900 & 7950 \\
\hline Methanol & 4660 & 2540 & 4120 & 4460 \\
\hline 1-propanol & 159 & $<100$ & 519 & $<100$ \\
\hline 2-propanol & 384 & $<100$ & 934 & $<100$ \\
\hline Ethylene glycol & 1690 & 1750 & 2050 & 3000 \\
\hline Propylene glycol & 7680 & 5800 & 5710 & 620 \\
\hline 1-butanol & 321 & $<100$ & $<100$ & $<100$ \\
\hline 2-Methyl-1-butanol & 104 & $<100$ & $<100$ & $<100$ \\
\hline 3-Methyl-1-butanol & 162 & $<100$ & $<100$ & $<100$ \\
\hline 2-Methyl-1-propanol & 154 & $<100$ & $<100$ & $<100$ \\
\hline 1-pentanol & 118 & $<100$ & $<100$ & $<100$ \\
\hline Methylsulfone & 150 & 26 & $<40$ & $<40$ \\
\hline DMSD & 37100 & $<400$ & 41900 & $<400$ \\
\hline *R\&R: Removal and Replacement of MF Bed & & \\
\hline
\end{tabular}

The Catalytic Reactor was tested at both the supplier (United Technologies Aerospace Systems, UTAS) and at the Marshall Space Flight (MSFC) ECLS Test Facility. Small column tests were performed at UTAS that indicated the reactor did not have enough capacity for the DMSD observed in the MF Bed effluent, and that there was a slight degradation of the reactor performance. Subsequently, a full scale reactor challenge was performed at MSFC in which the reactor was challenged with an organic load as defined in Table 2. During this test, the reactor was initially challenged for 5 days with the volatile organics expected on ISS (baseline solution), in which the product TOC was removed to $<1 \mathrm{mg} / \mathrm{L}$. For Test Days 5-30, DMSD was added to the feed, with the results as shown in Figure 5. For the remainder of the test, a small concentration $(0.2 \mathrm{mg} / \mathrm{L})$ of dimethylsulfone was added along with the DMSD to see if dimethylsulfone could be impacting reactor performance. This test confirmed the reactor could only oxidize approximately $78 \%$ of the DMSD, but did not show any measurable degradation in reactor performance. This observation has been corroborated by the on-orbit performance, which showed the original Catalytic Reactor installed in 2010 return to nominal performance after the MF Beds were replaced (thus removing DMSD from the reactor influent). This test data indicates the reactor would be nominally oxidizing the DMSD to a concentration of approximately 5 to $10 \mathrm{mg} / \mathrm{L}$ in the reactor effluent.

Table 2. Ersatz Formulation for DMSD Challenge

\begin{tabular}{|c|c|c|c|}
\hline Compound & $\begin{array}{l}\text { Baseline } \\
\text { Solution }\end{array}$ & $\begin{array}{l}\text { DMSD } \\
\text { Challenge }\end{array}$ & $\begin{array}{l}\text { Dimethylsulfone } \\
\text { Challenge }\end{array}$ \\
\hline Acetone & $5 \mathrm{mg} / \mathrm{L}$ & $5 \mathrm{mg} / \mathrm{L}$ & $5 \mathrm{mg} / \mathrm{L}$ \\
\hline Ethanol & $15 \mathrm{mg} / \mathrm{L}$ & $15 \mathrm{mg} / \mathrm{L}$ & $15 \mathrm{mg} / \mathrm{L}$ \\
\hline Methanol & $10 \mathrm{mg} / \mathrm{L}$ & * & * \\
\hline 1-propanol & $0.2 \mathrm{mg} / \mathrm{L}$ & $0.2 \mathrm{mg} / \mathrm{L}$ & $0.2 \mathrm{mg} / \mathrm{L}$ \\
\hline 2-propanol & $0.4 \mathrm{mg} / \mathrm{L}$ & $0.4 \mathrm{mg} / \mathrm{L}$ & $0.4 \mathrm{mg} / \mathrm{L}$ \\
\hline Ethylene glycol & $1.7 \mathrm{mg} / \mathrm{L}$ & $1.7 \mathrm{mg} / \mathrm{L}$ & $1.7 \mathrm{mg} / \mathrm{L}$ \\
\hline Propylene glycol & $8 \mathrm{mg} / \mathrm{L}$ & $8 \mathrm{mg} / \mathrm{L}$ & $8 \mathrm{mg} / \mathrm{L}$ \\
\hline 1-butanol & $0.4 \mathrm{mg} / \mathrm{L}$ & $0.4 \mathrm{mg} / \mathrm{L}$ & $0.4 \mathrm{mg} / \mathrm{L}$ \\
\hline 2-methyl-2-propanol & $0.4 \mathrm{mg} / \mathrm{L}$ & $0.4 \mathrm{mg} / \mathrm{L}$ & $0.4 \mathrm{mg} / \mathrm{L}$ \\
\hline Dimethoxydimethylsilane* & None & $40 \mathrm{mg} / \mathrm{L}$ & $40 \mathrm{mg} / \mathrm{L}$ \\
\hline Dimethylsulfone & None & None & $0.2 \mathrm{mg} / \mathrm{L}$ \\
\hline Theoretical TOC & $20.0 \mathrm{mg} / \mathrm{L}$ & $32.2 \mathrm{mg} / \mathrm{L}$ & $32.3 \mathrm{mg} / \mathrm{L}$ \\
\hline
\end{tabular}




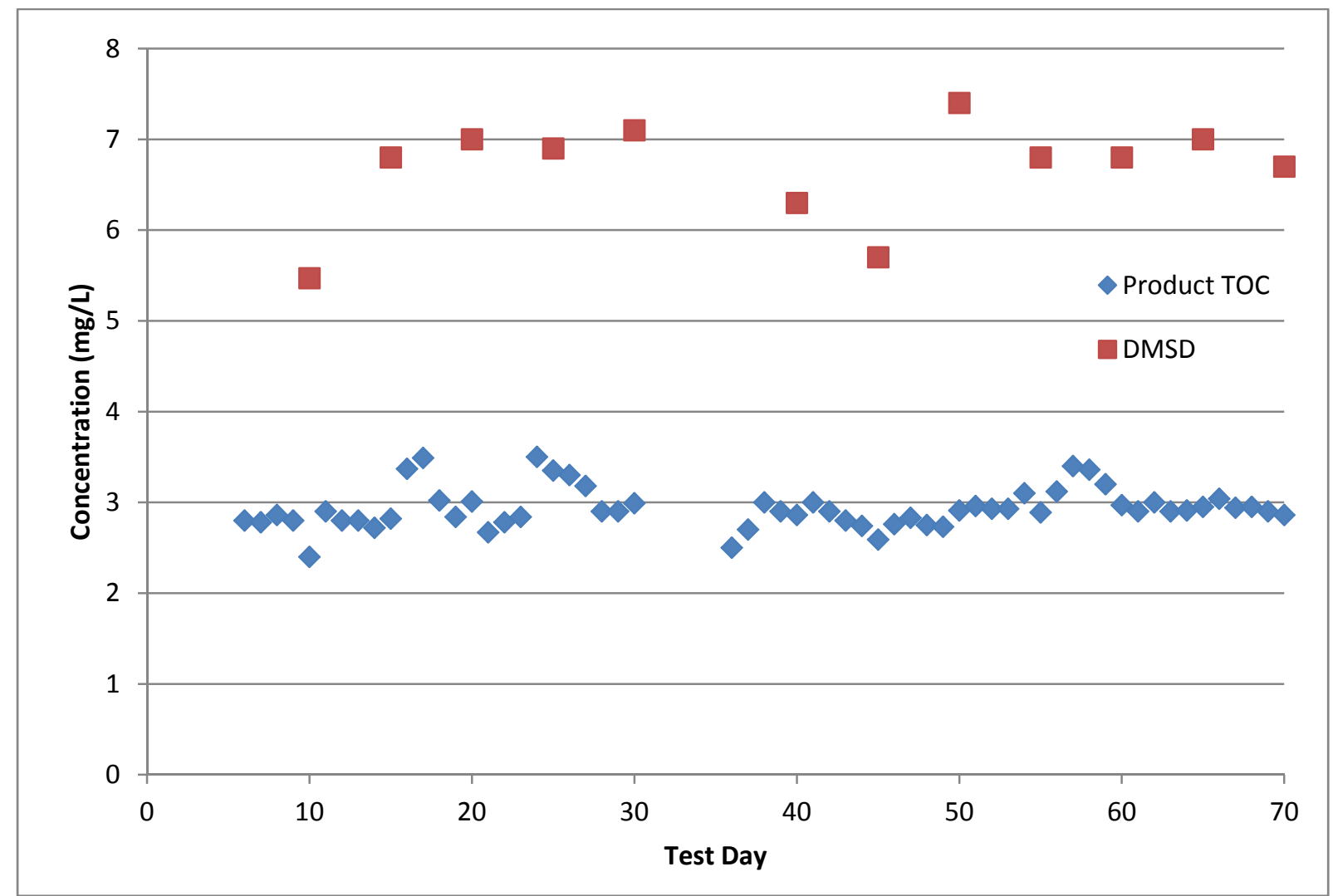

Figure 5. Reactor Effluent Data for DMSD Test

\section{TOC Analyzer Trend}

The most perplexing issue addressed during this investigation was the unique trend reported by the TOCA due to the presence of DMSD in the product water. The increase in TOC was initially suspected to be due to reactor poisoning, presumably organics that had saturated the MF Beds. However, replacement of both MF Beds in 2010 and 2012 (as well as the Catalytic Reactor in 2012) did not prevent the TOC from continuing to increase (see Figure 3). In 2010, the TOC trend recovered without any obvious operational change to the WPA. In 2012, suspecting the Ion Exchange Bed as the key to the unique TOC trend, engineering personnel had it replaced, which resulted in the immediate recovery of the TOC to nominal levels in the product water. This result led the team to conjecture that DMSD was eluting off the resin in the Ion Exchange Bed. To verify the role of the Ion Exchange Bed in the DMSD/TOC trend, tests were performed at UTAS to confirm its capacity for DMSD and to develop a viable explanation for the increasing TOC after removal of the MF Beds.

\section{Test Results}

The Ion Exchange Bed test was conducted to determine the performance of the IX Bed under conditions representing those of the flight unit during the TOC trend. The IX bed was scaled down by a factor of 8.5, while maintaining a length/diameter ratio of 7.5 (consistent with the flight IX Bed design). As with the flight unit, the IX Bed included two columns. The first column consisting entirely of IRN78 and the second column consisting of IRN78, IRN150 and the MCV resin in similar ratios to those used in the IX bed. The ground test was performed at a flow rate of $0.8 \mathrm{in}^{3} / \mathrm{min}\left(13 \mathrm{~cm}^{3} / \mathrm{min}\right)$, resulting in an overall retention time of 15 minutes assuming a $30 \%$ bed void volume.

Two series of challenge solutions were conducted to elucidate information regarding DMSD behavior in the IX bed. The first series included feeding the IX Bed with three consecutive solutions. First, the IX Bed was fed a 10 mg-DMSD/L solution. This solution represented the expected reactor effluent when the reactor was being fed 40 $\mathrm{mg} / \mathrm{L}$ of DMSD from the MF Bed. This feed continued until the IX Bed effluent TOC reached approximately 3 $\mathrm{mg} / \mathrm{L}$ (see Figure 7), simulating the ISS data during the TOC trend. This occurred after approximately $230 \mathrm{~kg}$ (500 
lb) of throughput. Second, deionized water was fed to the IX Bed to simulate the reactor effluent after installing a new MF bed. New MF Beds initially remove the alcohols typically treated by the reactor. Therefore, since there is no organic content in the MF Bed effluent, the reactor effluent is not expected to contain any significant concentration of bicarbonate (primary oxidation product of the organics in the reactor influent). This solution was fed to the IX Bed while the effect on the DMSD concentration in the effluent was monitored. For approximately 70 L (150 lb) of throughput, the DMSD and TOC concentrations remained relatively level, showing that the DI water was effectively eluting the DMSD. However, it was evident that there would be no increasing trend consistent with that observed on ISS. Finally, a $10 \mathrm{mg}-\mathrm{NaHCO}_{3} / \mathrm{L}$ (sodium bicarbonate) solution was fed to the IX Bed to simulate the reactor effluent after the volatile organics passed through the MF Bed. After $20 \mathrm{~L}(50 \mathrm{lb})$ of throughput, the DMSD and TOC concentrations began to decrease (see Figure 7). These results also did not represent the characteristic signature of the ISS TOC trend, most likely due to the DI water flush removing enough of the DMSD to prevent a response when the bed was challenged with the bicarbonate flush.

In the second series of challenge solutions, the Ion Exchange Bed was saturated with DMSD using the $10 \mathrm{mg}$ DMSD/L solution, which again required approximately $230 \mathrm{~kg}(500 \mathrm{lb})$ of throughput. Subsequently, the bed was challenged with the $10 \mathrm{mg}-\mathrm{NaHCO}_{3} / \mathrm{L}$ flush (no DI water flush). These results are provided in Figure 8 . Though the DMSD and TOC concentrations initially decreased when challenged with bicarbonate, they subsequently increased for approximately $50 \mathrm{~L}(120 \mathrm{lb})$ of throughput, consistent with the ISS trend. Figure 9 shows the data from ISS and both ground tests normalized based on throughput. These tests showed that DMSD elution from the scaled IX bed occurred with both DI water and the bicarbonate feed and exhibited a similar trend to those observed with the product water TOC events on-orbit. The primary difference in the ground versus on-orbit data was that the increasing TOC trend could not be fully replicated as it occurred on ISS. Regardless of this discrepancy, the ground and on-orbit data trended well with respect to increasing TOC concentrations due to DMSD bed breakthrough.

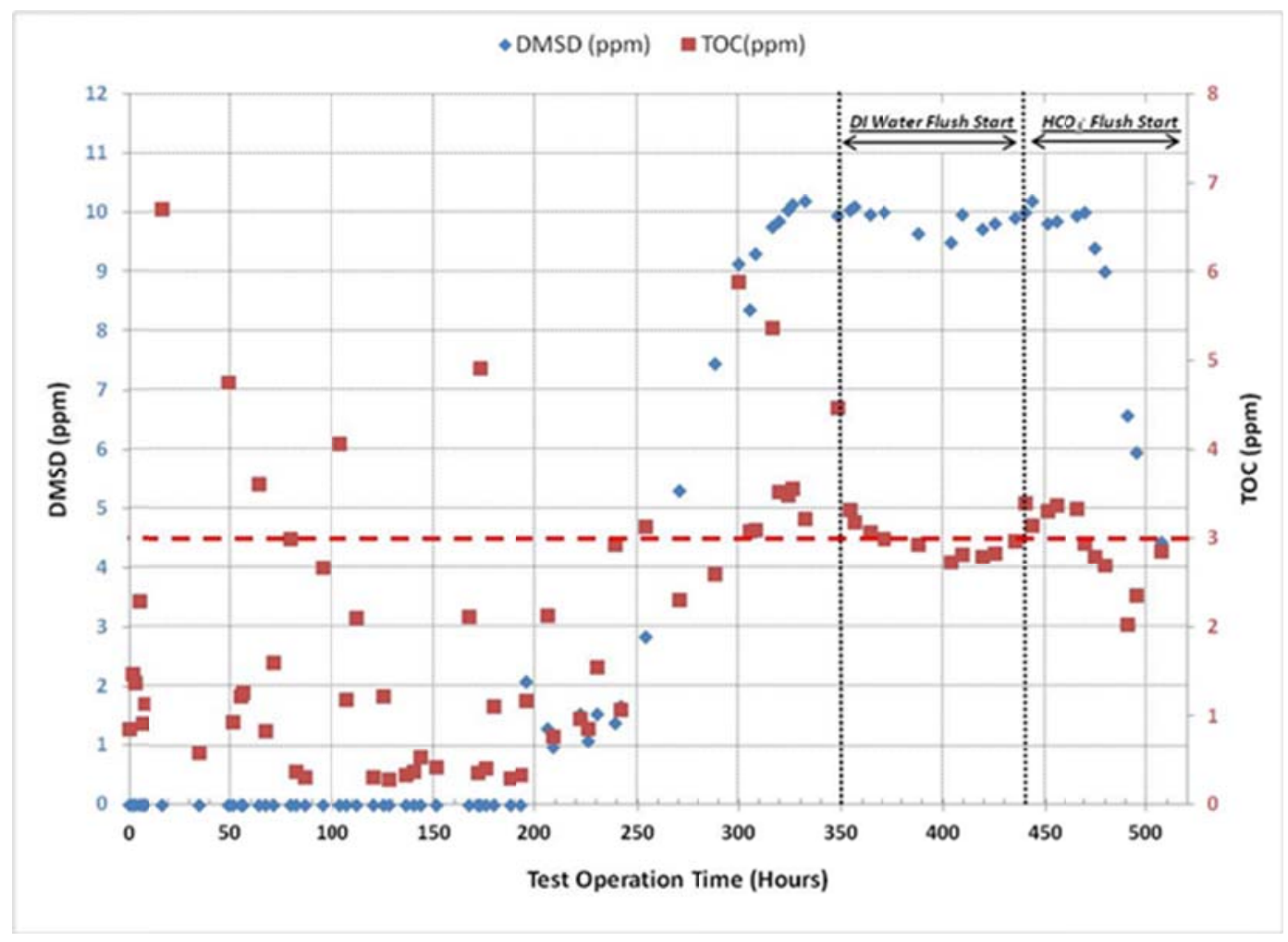

Figure 7. DMSD loading and elution from first WPA IX bed challenge 


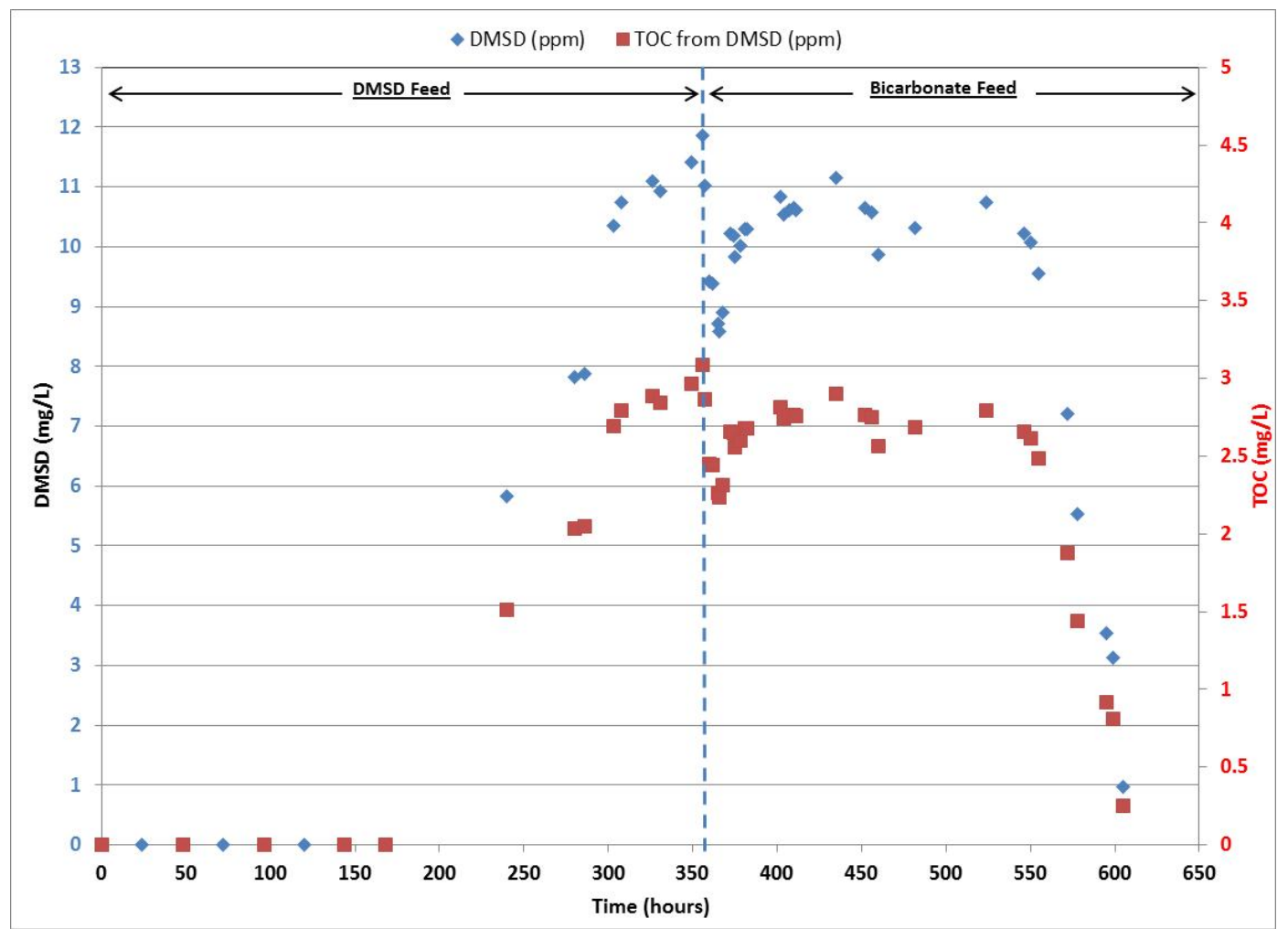

Figure 8. DMSD loading and elution from second WPA IX bed challenge

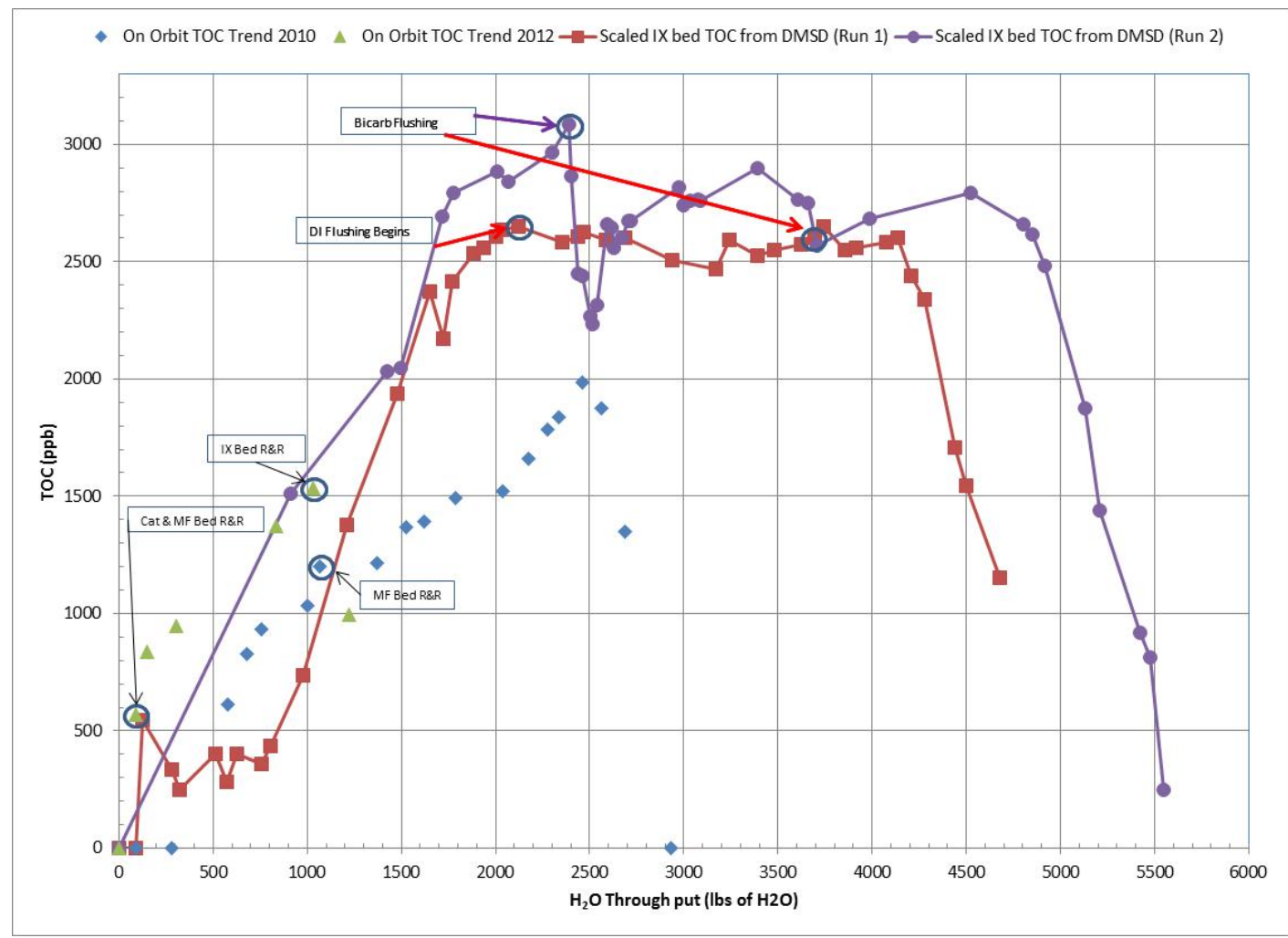

Figure 9. Comparison of DMSD elution from scaled IX bed and TOC events observed on-orbit.

American Institute of Aeronautics and Astronautics 


\section{Problem Resolution}

Based on the investigation performed by ISS engineering personnel, the DMSD is present in the product water because it is inadequately removed by the various WPA treatment processes. Though the MF Beds have limited capacity for DMSD, eventually it is displaced (most likely by bicarbonate) and enters the Catalytic Reactor. At the concentrations measured in the MF Bed effluent (approximately $40 \mathrm{mg} / \mathrm{L}$ ), ground tests indicate DMSD will be present in the reactor effluent at approximately $10 \mathrm{mg} / \mathrm{L}$. This concentration of DMSD will saturate the Ion Exchange Bed, and exhibit the breakthrough curve provided by the ISS TOC Analyzer as shown in Figure 2. The increasing TOC trend after replacing the MF Beds (and Catalytic Reactor in 2012) is due to initial displacement of the DMSD by bicarbonate. Once this process is complete, the TOC concentration in the product water quickly drops to a nominal concentration that is below the TOC Analyzer detection limit.

The path forward for DMSD is challenging. Though it is not toxic to ISS crew at the levels observed in the WPA, it is not safe to operate the WPA under these circumstances. First, DMSD exceeds the capacity of the reactor, and would therefore also potentially impact the ability of the reactor to oxidize other organics. This could result in the presence of harmful organics in the reactor effluent and ultimately the product water. Second, if DMSD is present in the product water, it could mask the presence of more toxic contaminants in the TOC Analyzer results. For these reasons, a plan must be developed for removing DMSD in the WPA and preventing it from reaching the product water.

The viable processes in the WPA for removing DMSD include the MF Beds and the Catalytic Reactor. Since silicon-based media is effective in isolating DMSD and PDMSs in analytical methods, engineering personnel anticipated media existed that would be effective for removing DMSD in the MF Beds. Unfortunately, no media could be identified that had any significant capacity for DMSD, including activated carbon or silicon-based media.

Another option is to improve the Catalytic Reactor performance to achieve complete removal of the DMSD. Since ground tests showed a full-scale reactor could remove almost $80 \%$ of the DMSD, it is logical that an incremental improvement in reactor performance could achieve $100 \%$ removal of the DMSD. This could conceivably be accomplished by increasing the reactor temperature, residence time, or flow rate of oxygen. Tests are currently underway to evaluate reactor performance under varying conditions. Unfortunately, the design of the Catalytic Reactor has minimal flexibility. Operating temperature limits would prevent any significant increase in the reactor temperature, requiring a redesign of the reactor and the WPA controller. Furthermore, there is limited volume available to increase the reactor size to provide more residence time. This option will only be pursued if the test results prove it is viable, and more cost-effective processes cannot be identified.

Another option would be to identify the source of the DMSD, and remove that source. As discussed previously, however, the source of DMSD is not easily found. Analysis of ISS cabin air only targets 3 PDMSs, though there are certainly more in the ISS atmosphere. A significant research effort would be required to identify all of the siloxanes present in the air, and subsequently determine which of them can degrade to form DMSD. Finally, even if this task could be accomplished, removing the source of the PDMS may not be viable. The materials on ISS that off-gas the PDMSs are inherent in the ISS infrastructure and eliminating them would be costly and may not be possible given their specific application. This option would only be viable if the source of DMSD can be definitively isolated, and the specific PDMS is from a unique material that can be readily removed or replaced on ISS.

The preferred option is to prevent DMSD from condensing in the ISS condensate. Removal of organosilicon compounds from the air is inherently more efficient than removal from water. However, there are issues with this approach as well. First, the specific path by which DMSD is produced in the condensate is not known. Without understanding the actual mechanism, a treatment process must be sufficiently global to address all possible sources. To mitigate this uncertainty, bench tests are being developed that will provide further definition on how DMSD is produced in the condensate. Depending on the outcome of this investigation, a treatment process must be developed that can remove both PDMS and DMSD from the air. This process must be sufficiently selective for these organosilicon compounds such that its capacity is not exceeded with competition from other volatile compounds. Finally, the design of this treatment process must be integrated into the existing Condensing Heat Exchanger on ISS. The design for the treatment process must consider the fact that there is limited pressure drop available in this location. Furthermore, the design must fit within the limited volume available at the inlet to the heat exchanger while addressing the specific procedure by which the crew would install and maintain the new hardware. 


\section{Conclusion}

The recurrence of the DMSD trend in 2012 provided critical data in identifying the path by which DMSD passed through the WPA and caused the unique trend reported by the ISS TOC Analyzer. Engineers and scientists were able to use this data to logically deduce the fate of DMSD in the WPA. This effort has determined that the MF Beds and Ion Exchange Bed in the WPA have limited capacity for DMSD, and the Catalytic Reactor has insufficient capacity for the expected concentrations. Based on this current understanding, engineering personnel are developing other treatment processes for removal of DMSD.

\section{Acknowledgments}

The authors wish to acknowledge the effort of the many engineers and scientists at NASA MSFC/JSC, Hamilton Sundstrand, Boeing, and Umpqua Research Company that have performed excellent work in the last three years toward identifying DMSD as the source of the TOC trend in the WPA product water, and developing an understanding of the fate of DMSD in the WPA.

\section{References}

1. McCoy, T., S. Flint, J. Straub II, D. Gazda, and J. Schultz, The Story Behind the Numbers: Lessons Learned from the Integration of Monitoring Resources in Addressing an ISS Water Quality Anomaly, AIAA 1020578, presented at the 41 International Conference on Environmental Systems, Portland, Oregon, July, 2011.

2. $\quad$ Personal Email Correspondence, J. Perry, Re: DMSD Question, 03 May 2013

3. Environment Canada, Report of the Board of Review for Decamethylcyclopentasiloxane (Siloxane D5), Ottawa, ON, Canada, October 20, 2011

4. Gazda

5. Fabien Chainet, Charles-Philippe Lienemann, Marion Courtiade, Jeremie Ponthusa, and Olivier Francois Xavier Donard, "Silicon Speciation by Hyphenated Techniques for Environmental, Biological and Industrial Issues: A Review" Journal of Analytical Atomic Spectrometry, 2011, 26, 30

6. Environmental Information Update, “Degradation of Silicone Polymers in Nature”, Dow Corning Corp., Copyright 1998

7. Environmental Information Update, “An Overview of Polydimethylsiloxane (PDMS) Fluids in the Environment”, Dow Corning Corp., Copyright 1997

8. Xu, Shihe, Robert G. Lehman, Jack R. Miller, and Grish Chandra, "Degradation of Polydimethylsiloxanes (Silicones) as Influenced by Clay Minerals”, Environmental Science Technology, 1998, 32, 1199-1206

9. Schwartz, W., Laliberte, Y., Heat Exchanger ORU SV813900-2 S/N 001, Test, Teardown and Evaluation Final Report, Hamilton Sundstrand Internal Report, August 12, 2009

10. Carter, D.L., B. Tobias, N. Orozco, "Status of the Regenerative ECLSS Water Recovery System", AIAA 1278029, presented at the $42^{\text {nd }}$ International Conference on Environmental Systems, San Diego, California, July, 2012

11. Carter, D.L., N. Orozco, “Status of the Regenerative ECLSS Water Recovery System”, AIAA 1021863, presented at the 41 International Conference on Environmental Systems, Portland, Oregon, July, 2011.

12. Carter, D.L., "Status of the Regenerative ECLSS Water Recovery System", AIAA 758248, presented at the 40" International Conference on Environmental Systems, Barcelona, Spain, July, 2010.

13. Carter, D.L., "Status of the Regenerative ECLSS Water Recovery System", SAE 2009-01-2352, presented at the 39"th International Conference on Environmental Systems, Savannah, Georgia, July, 2009.

14. Muirhead, Dean, Evaluation of Alternative Pretreatment Formulations for Minimizing the Risk of Mineral Precipitation During Distillation of Urine, ESCG-4106-12-CHLSS-DOC-0002, January 2012

15. Bowman, B, M. Wilson, H. Cole, N. Orozco, and D.L. Carter, Performance Evaluation of the ISS Water Processor Multifiltration Beds, AIAA 1277990, presented at the $42^{\text {nd }}$ International Conference on Environmental Systems, San Diego, California, July 2012

16. Personal Email Correspondence, J. Straub, Latest TOCA Results, 07 June 2012 